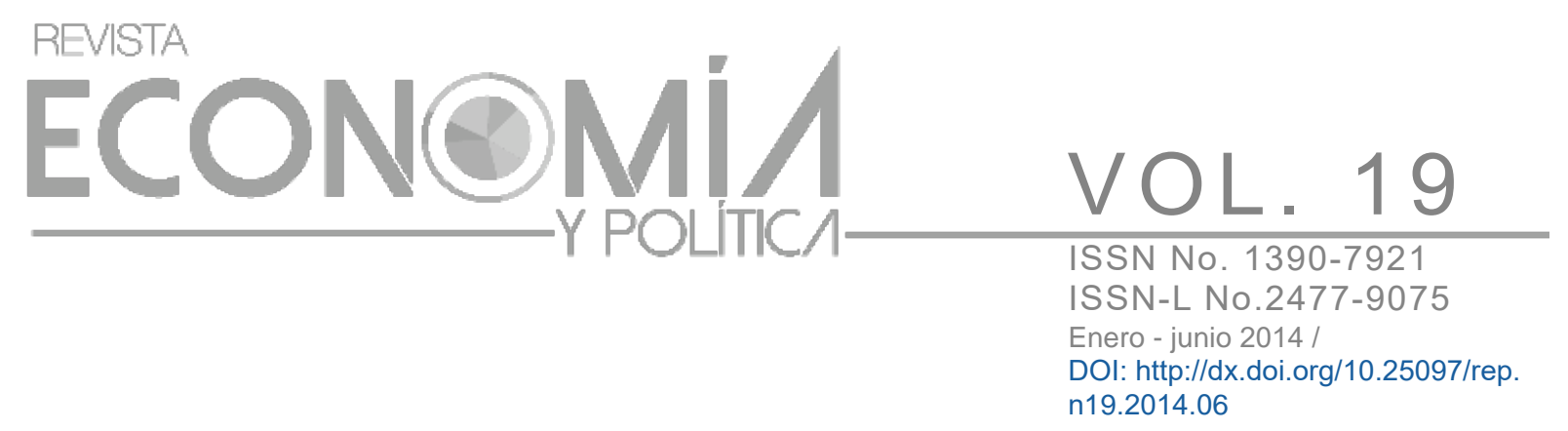

\title{
LA PARTICIPACIÓN SOCIAL VA MAS CON EL BUEN VIVIR QUE CON EL DESARROLLO
}

\section{THE SOCIAL PARTICIPATION IS MORE THE GOOD LIFE THAT WITH THE DEVELOPMENT}

\section{Resumen}

José Astudillo Banegas Universidad de Cuenca.

jose.astudillob@ucuenca.edu.ec

Durante la últimas décadas y con una fuerte influencia del siglo anterior, hemos estado denodadamente hablando, esperando y construyendo el Desarrollo, pues, la postguerra nos heredó el anhelo de llegar a ser a imagen y semejanza de los Estados Unidos, y siguiendo el discurso de presidente Harry Truman, en el punto cuarto, quedó el mundo globalizado, como diría Carlos Marx, bajo el efecto del opio de la industrialización y el desarrollo económico; sacrificando pueblos, extrayendo recursos naturales sin medirlas consecuencias, monetarizando la tierra en su máxima expresión, etc. En este proceso la participación es solo un slogan. La participación Social en su verdadera dimensión va más con la Búsqueda del buen Vivir, o como diría Tomás R.-Villasante, mejorar las cosas cada día para vivir mejor (RVillasante, 2013), sin tratar de obtener la verdad absoluta, sino de conseguir la felicidad. "vivir de otro modo para vivir mejor" (Latouche, 2003). Involucrar a la gente en las cosas que desea hacer para crecer y lograr su desenvolvimiento, hacer con ellos y no para ellos: "sólo el compromiso con la regla del desarrollo, conlleva el compromiso con la subordinación de los objetivos medios (crecimiento económico y desarrollo tecnológico) a los objetivos fines: mejoría de las condiciones, el nivel y la calidad de vida para todas las formas de vida en el planeta" (Lima, S.M.V., A.M., Gomes de Castro, O. Mengo, M. Medina, A. Maestrey, V. Trujillo y O. Alfaro. 2001).

Palabras claves: Desarrollo, Desarrollos alternativos, Buen Vivir, Límites deldesarrollo, Participación Social, Planificación Participativa.

\begin{abstract}
During the last decades, with a strong influence of the previous century, we have been tirelessly talking , waiting and building a Development, therefore postwar inherited us the desire to become the image and likeness of the United States, following the speech of Hamy Truman President, the fourth point, was the globalized world, as Karl Marx would say, under the influence of opium of industrialization and economic development ; sacrificing people, extracting natural resources without considering the consequences, monetarizando land at its finest etc. . Participation in this process is just a slogan. Social participation in its true dimension goes in the search of Good live, or like Thomas R. Villasante would say improve things every day to live better (R-Villasante , 2013), without trying to get the absolute truth, but to achieve happiness. "Live differently for better living " ( Latouche , 2003). Involve people in the things they want to do to grow and achieve their development, do with them and not for them, " only the commitment to the rule of development entails to a commitment to the subordination of means objectives (economic growth and technological development) to the end objectives : improved conditions, the level and quality of life for all life forms on the planet " (Lima, SMV , AM, Gomes de Castro , O. Mengo , M. Medina , A. Maestrey , V. Alfaro and O.Trujillo . 2001)
\end{abstract}

Key words: Development, Alternative Development, Good Living, Limitations to development, Social Participation, Participatory Planning. 


\section{CONCEPTOS DE "DESARROLLO".}

Para muchos autores el desarrollo es entendido como: Progreso. El crecimiento de la persona a nivel económico, político, social, espiritual se remonta hacia los mismos orígenes de la humanidad y el pensamiento de algunas culturas, entre ellas los griegos. Aristóteles hablaba de Zóon Politikon, considerando al hombre como un ser; ciudadano, participante de la vida cívica en la ciudad.

Las antiguas reflexiones filosóficas en relación con el desarrollo de la persona, la muestran como sujeto activo y no pasivo u objeto (Esclavitud); el crecimiento económico siempre estuvo cercado por la propiedad privada, la acumulación y la reglamentación de la misma.

Federico Engels, critica al Estado desde sus orígenes en la sociedad griega, como el regulador del crecimiento y la acumulación de la propiedad privada, más tarde esto será entendido como el Desarrollo Económico:

"No faltaba más que una cosa; una institución que no solo asegurase las nuevas riquezas de los individuos contra las tradiciones comunistas de la constitución gentil, que no solo consagrase la propiedad privada antes tan poco estimada e hiciese de esta santificación el fin más elevado de la comunidad humana" (Federico Engels, 2008, p.112).

Para la modernidad, el progreso, el desarrollo, será cuantificación de la materia: suelo, producción, productividad, etc., lo que genera riqueza, en el pensamiento de los fisiócratas, y más tarde el trabajo incorporado en la materia prima. El trabajo mismo será la riqueza y el desarrollo de las naciones según Adam Smith. Pues el trabajo separado de la materia prima se vuelve en un bien en sí mismo para ser vendido, los hombres podrán desarrollarse según más trabajo pueda realizar, vender o esclavizarse a través de esta venta.

Así se expresa Adam Smith (Aguirre Manuel, 1970) cuando se refiere al crecimiento de la riqueza y la consecución de los bienes para poder gozar de las cosas necesarias y convenientes para la vida: "La mayor parte de ellas se conseguirán mediante el trabajo de otras personas, y será rico o pobre, de acuerdo con la cantidad de trabajo ajeno que pueda disponer o se halle en condiciones de adquirir" (p. 31). 
Las concepciones clásicas, formales, instituidas, a ser transmitidas por el sistema mundo capitalista (Wallerstein, Immanuel, 2004), tienen que ver con el crecimiento económico y la apropiación, ya no solo de los bienes materiales, la materia prima, los bienes transformados, sino con la persona misma a través de su fuerza de trabajo.

El mundo post-moderno construye una aparente racionalidad del desarrollo. Sacudido por la estrategia milenaria de crecimiento y progreso viene a concluir en las guerras. El mundo queda devastado después de la Segunda Guerra Mundial de 1945, donde se dirimió por fin la nueva hegemonía de los Estados Unidos de América del Norte. Hegemonía política, comercial, y de seguridad (industria armamentista), hasta la fecha.

Correspondió entonces al Presidente de los Estados Unidos de América del Norte, trazar las nuevas directrices de lo que se considera "Desarrollo" para todo el mundo, y es en el discurso pronunciado por Harry Truman, como expresa Rist Gilbert (2002), en donde se da la reinvención del desarrollo, invención que más parece asemejarse al descubrimiento del territorio que sería denominado como las Américas. ¿Qué descubrimiento?, ¿Qué invención del desarrollo?, si todo estaba dado, se ve que lo bueno para Estados Unidos de Norte América será bueno para todo el mundo.

El cuarto punto del discurso proclamado por Harry Truman presidente de los Estados Unidos de Norte América que funda el concepto de Desarrollo aplicado hasta nuestros días, dice lo siguiente:

"Cuarto. Debemos lanzarnos a un nuevo y audaz programa que permita poner nuestros avances científicos y nuestros progresos industriales a disposición de las regiones insuficientemente desarrolladas para su mejoramiento y crecimiento económico...

Los Estados Unidos se destacan entre los países del mundo entero por el desarrollo de sus técnicas industriales y científicas. Los recursos materiales que podemos utilizar para ayudar a otros pueblos son limitados. Pero nuestros inconmensurables recursos en materia de conocimientos técnicos se encuentran en constante crecimiento y son inagotables...

Únicamente ayudando a los menos afortunados de sus miembros a ayudarse a sí mismos, puede la familia humana lograr la vida digna $y$ satisfactoria a la que tienen derecho todos los pueblos..." (Rist, 2002, pp. $85-86)$. 
El concepto de Desarrollo expresado por el representante del nuevo imperio mundial en 1948, legitima de esta manera, la pobreza, el subdesarrollo y se siente enviado por fuerzas divinas a ayudar a los menos favorecidos desechando el análisis marxista, de que las cosas no son por simple casualidad sino por una causalidades.

Si Federico Engels citó a la sociedad griega como la madre del Estado símbolo de la estructura de poder y reglamentación de la propiedad privada, habrá que citar el discurso de Harry Truman, como el nuevo Estado Supra-mundial que regulará lo que se debe hacer y específicamente lo que será el Desarrollo, la nueva civilización para todos los seres humanos en el mundo.

\subsection{EL DESARROLLO SOSTENIBLE}

El crecimiento cero y desarrollo sostenible, nos parecen epítetos equívocos, debido a que no tienen que ver con el desenvolvimiento equitativo de las personas y el equilibrio planetario, sino más bien con la regulación del consumo y el crecimiento. Surgen de dos informes: El Club de Roma y más tarde el Brundtland, como preocupación del crecimiento económico, apenas en 30 años entre 1945 y 1975, y la consecuente degradación de los recursos naturales.

El Informe al Club de Roma Publicado por Meadows, titulado "Los límites del crecimiento", enfatiza que; desarrollo y medio ambiente van de la mano. En este mismo informe se realiza la propuesta de "crecimiento cero":

"Más allá del eslogan del "crecimiento cero" que ha marcado los espiritus y ha sido objeto de discusiones, incluso en el Club de Roma, se plantea el problema del reparto de las riquezas a nivel mundial. Para ello, el crecimiento debe producirse en los países del Sur, al menos durante cierto tiempo, e interrumpirse en los países del Norte" (Urteaga, 2008, p.128).

Las reflexiones del Club de Roma continúan en cuanto a los límites del desarrollo y será en 1974 Mesarovic y Pestel, quienes propongan «definir el desarrollo razonable para tal región, teniendo en cuenta los recursos disponibles para la población, de sus coacciones y de sus interdependencias de cualquier naturaleza» (Urteaga, 2008, p. 128)

En 1986 la propia Comisión Mundial del Medio Ambiente y Desarrollo, estandariza el pensamiento del Desarrollo Sostenible, a través del Informe Brundtland que sitúa la problemática mundial, como la falta de acceso a los recursos por parte de la mayoría de los habitantes del planeta, pues uno de sus objetivos es: "Satisfacer las necesidades esenciales de trabajo, alimentos, energía, agua, higiene" (Herrero, 1997), sin comprometer a las generaciones futuras. Dos enfoques proponen este informe:

“a) El de necesidades, en particular las esenciales de los pobres, a los que se deberá otorgar prioridad preponderante. 
b) La idea de las limitaciones que imponen los recursos del medio ambiente, el estado actual de la tecnología y de la organización social y la capacidad de la biosfera de absorber los efectos de las actividades humanas" (Herrero, 1997, $p$. 56)

Más allá de los esfuerzos de las dos comisiones lo que queda claro es la preocupación por detener el crecimiento, posibilitar el acceso a los recursos por parte de los sectores empobrecidos y conservar el ambiente, aunque el mismo informe Brundtland, al hablar de sostenibilidad, sitúa la insostenibilidad al que nos ha llevado el sistema industrial. Varios autores (Naredo, etc.) han señalado las contradicciones de apostar al tiempo por el "desarrollo" y por la "sostenibilidad", que parecen incompatibles tal como hoy se han venido entendiendo.

\section{2.- DESARROLLOS ALTERNATIVOS}

Hoy la sociedad tiene una responsabilidad compartida de acabar con el sistema de trabajo en condiciones de servidumbre, mejorar las libertades de las mujeres, erradicar el trabajo infantil, derecho a la educación, derecho a vivienda, derecho a salud, etc. Desde esta perspectiva autores como Amartya Sen y Manfred Max Neff, se enfocan en crear unas propuestas alternativas al desarrollo económico tradicional.

Amartya Sen basa sus estudios en la expansión de las capacidades y libertades fundamentales para el enriquecimiento de la vida humana.

"Entre las libertades fundamentales se encuentran capacidades elementales como: la inanición, la desnutrición, la morbilidad evitable y la mortalidad prematura, o gozar de las libertades relacionadas con la capacidad de leer, escribir y calcular, participación política, libertad de expresión, etc. Desde esta perspectiva el desarrollo ha de basarse en la expansión de estas y otras libertades básicas." (Sen, 1997, pág. 55)

Por lo tanto el aumento de la libertad del hombre debe ser el principal objetivo del desarrollo y la valoración de las libertades reales que goza cada individuo o ser humano. Las capacidades de un individuo dependen de los sistemas económicos, sociales y políticos, el Estado y la sociedad deben reforzar y salvaguardar las capacidades humanas. La capacidad de una persona hace referencia a diversas combinaciones de funciones que puede conseguir, la combinación de funciones que una persona refleja sus logros (lo que una persona es capaz de hacer). Claro está que el desarrollo de las capacidades va a depender mucho de cuantas libertades fundamentales se tenga, no va ser lo mismo ayunar que verse obligado a pasar hambre, la pobreza priva las capacidades. (Sen, 1997, págs. 29-114).

Max Neff, Elizalde y Hopenhayn plantean un Desarrollo a Escala Humana orientado hacia "los satisfactores" de las necesidades humanas, ha de entenderse a las necesidades no solo como carencias sino también como potencialidades humanas individuales y colectivas. 
Las personas tienen necesidades múltiples e interdependientes, por ello las necesidades deben entenderse como un sistema en que las mismas se interrelacionan e interactúan. Las necesidades son finitas y pocas y clasificables y son las mismas en todas las culturas y en todos los períodos históricos. Las necesidades pueden ser existenciales: Ser, Tener, Hacer y Estar; axiológicas: de subsistencia, protección, afecto, entendimiento, participación, ocio, creación, identidad y libertad (Max Neff, 1993)

Los satisfactores cumplen su función frente a una necesidad sentida; una necesidad puede requerir de diversos satisfactores para ser satisfecha. Se satisface una necesidad de carácter individual y/o colectivo. Los bienes económicos permiten afectar solo a un satisfactor, de allí que para Max Neff, el desarrollo no se centra solo en lo económico, sino en la interrelación entre satisfactores, necesidades y bienes económicos, que desde su dialéctica histórica, están en permanente dinámica. (Max Neef, Manfred; Elizalde, Antonio; Hopenhayn, Martin. 1993, págs. 56-69)

\section{3.- LÍMITES DEL DESARROLLO Y ALTERNATIVAS.}

Escobar (2007), señala que en 1949, comienza la era del desarrollo a través del Plan Marshall y de la propuesta de Truman. Una era del desarrollo enfocado en el crecimiento económico de los pueblos, industrialización de los países y la indagación (investigación) de la naturaleza como objeto de conocimiento y transformación de la materia prima.

Técnica y capital inician un proceso "misionero" a nivel mundial (Escobar, 2007), pues, se tenía el convencimiento que la primera ayudaría a los pueblos desfavorecidos (en el vocabulario teológico - capitalista de Truman), a salir de sus "ignorancias", para poder producir el alimento, el vestido, la vivienda, el confort, para satisfacer las necesidades básicas y acumular como riqueza nacional. Se sabía que el discurso no correspondía a las verdaderas intenciones, pues siempre el capital estaba allí, no escondido, si agazapado. En alianza obscura los "misioneros" del desarrollo, sabían que al final su tarea fue desarrollar el capital hacia espacios ilimitados.

Superpuesto el capital a la técnica hemos llegado a una situación límite del crecimiento, provocando al menos cuatro grandes crisis, como advierte Tortosa (2012):

El límite del crecimiento económico, que se puede advertir en la financiarización de la economía, las burbujas financieras, como la ocurrida en el 2008 en los Estados Unidos de Norte América con la especulación de los créditos y bonos para la vivienda. El decrecimiento de la economía mundial ha llevado al desempleo, la falta de consumo, la subida de impuestos y como anuncia Tortosa: "Es posible que la depresión (que no recesión) sea duradera, pero sin cambiar en mucho el funcionamiento del sistema mundial, sus reglas del juego y su estructura" (Tortosa, 2012, p.39)

El límite Energético, que tiene que ver con la crisis del petróleo, hemos llegado al pico en la producción del petróleo, en cuanto al agotamiento de las fuentes así como del precio, en momentos a la baja y otras veces a la subida. Si la energía que mueve el 
mundo es el petróleo y este recurso escasea, la crisis se manifiesta "porque la energía en general y el petróleo en particular están imponiendo una transición energética en la que, de nuevo, lo viejo ya ha muerto, pero lo nuevo está por nacer" (Tortosa, 2012, p. 41).

El límite alimentario, la crisis de la alimentación mundial está muy vinculada, a la crisis energética, ya que se trata de cambiar la matriz energética del petróleo utilizando productos que sirven para alimentar a la población mundial, de allí que la tecnología no estará al servicio de la satisfacción de las necesidades humanas sino de los requerimientos de la gran maquinaria, pues,

"se trata de producir energía a partir de la agricultura: el trigo o el maíz, la soya o la caña de azúcar, o, incluso la biomasa de numerosas plantas como la palma oleaginosa (conocida como la palma africana) (Houtart, 2009, p. 37). La situación límite e irracional de producir para agro combustible hace que se eleven los precios de los alimentos y se pierda soberanía alimentaria, dándose estimaciones como de mil millones d hambrientos en el mundo en el año 2011, según datos de la FAO (Tortosa, 2012)

El límite ambiental, las situaciones que preocupan en este punto, entre otros, están: el re-calentamiento global; la emisión de $\mathrm{CO} 2$ por la contaminación de las fábricas, vehículos, quema de fósiles; consumo excesivo, y la preocupación del agotamiento de los recursos no renovables. Por ejemplo los Estados Unidos de Norte América, "en 2007 tuvieron que importar el $75 \%$ de su consumo. Son los consumidores de la cuarta parte del petróleo mundial y no poseen más que un $3 \%$ de las reservas conocidas" (Houtart, 2009, p.39), en este sentido advierte Houtart, "la crisis de las energías no renovables es real. Al ritmo actual su utilización agotaría la totalidad de las reservas mundiales en 2.100" (Houtart, 2009, p. 47).

Más allá de ahondar en datos que den cuenta de la gravedad de la crisis, lo que nos ha llevado el desarrollo es a una situación al borde del abismo, frente a esto debemos reaccionar. Villasante retomando la Sociedad del Riesgo propuesto por Ulrich Beck, plantea 12 plagas como límites del desarrollo. Organizadas en 4 grandes bloques, el primero sobre el Habitar y nuestra mala relación con la naturaleza, el segundo tiene que ver con el Trabajo y las consecuencias económicas del desempleo, el tercero es sobre los Poderes y las formas de organizarnos entre seres humanos y las violencias que se evidencian, y el cuarto el de las Culturas es la imposición de un pensamiento y forma de vida monolítica (Villasante, 2006). Esta plagas (límites del desarrollo), entre otras se expresan de la siguiente manera:

El límite de la Salud, como consecuencia de una mala y desigual alimentación. Villasante al hablar de esta plaga cita a Rifkin de la siguiente manera:

"El 61 por ciento de los estadounidenses adultos sufre de sobre peso (...) Según las Organización Mundial de la Salud (OMS), la razón es la "extendida adopción del estilo de vida basado en hamburguesas ricas en grasas". La OMS informa que, actualmente, el 18 por ciento de la población total mundial es 
obesa, prácticamente la misma cantidad de gente desnutrida”. (Villasante, 2006, p. 56)

El límite del desempleo, la teoría del desarrollo reimpulsada por $\mathrm{H}$. Truman con una fuerte influencia Keynesiana tiene que ver con el pleno empleo. El trabajo mueve la maquinaria y genera productos para el mercado, por lo tanto los trabajadores adquieren de una u otra manera un salario que le permite vivir. Lo que está pasando actuantemente es que los trabajos fijos están en crisis. "El número de los que están esperando para acceder a la condición de "explotados" es demasiado alto como para no sentir la presión de los que están sin ningún tipo de trabajo, o en condiciones laborales mucho peores", sin contar que se prevé el nacimiento de unas 2.000 .000 de personas en la próximas décadas. (Villasante, 2006, p. 62).

El límite de la inseguridad, pues estamos de vuelta a los castillos de la Edad Media, a través de las urbanizaciones privadas, verdaderos guetos de privilegio. Por otro lado existe una sin razón en la inversión armamentista, 900.000 millones gasta el mundo en cuidarse de la inseguridad mientras que (quitando todos los epítetos del rubro ayuda al desarrollo) solamente 1.000 millones llegan de ayuda al desarrollo anualmente (Villasante, 2006)

"Compárese con los 350.000 millones que los ricos dedican a subvenciones y barreras tarifarias. "Estamos locos en como abordamos el desarrollo, que es una cuestión de justicia global". Por el camino que hemos tomado cada vez se invierte más dinero en los negocios de armamentos, y menos en los de ayuda al desarrollo" (Villasante, 2006, p.67)

Muchos autores han analizado el Desarrollo, como simple crecimiento económico y han intentado encontrar una vía diferente al mismo. Pero si somos 7.000 millones sobre la tierra, hay 2.000 por nacer ¿que cabe hacer? ¿Parece lógico seguir por el mismo camino, o con algunas variantes que le pongan adjetivos, o más bien cambiar de camino?

Tortosa (2011) encuentra 4 intentos de superar la visión del crecimiento económico. La primera encargada a un grupo de economistas que elaborará un sistema de medición que fuese más allá del PIB que reconozca el crecimiento social; el segundo la iniciativa gubernamental del 2006 propuesta por el rey Jigme Khesar que propone medir la Felicidad Nacional Bruta teniendo en cuenta el bienestar psicológico, salud, uso de tiempo, entre otros; el tercer intento es de algunos "altermundistas", como Walden Bello o Theotonio Dos Santos que proponen eliminar la división de desarrollados o subdesarrollados,, mejorando la calidad de vida, maximizar la equidad y reducir el desequilibrio ambiental; un cuarto punto hace referencia a las experiencias de los estados latinoamericanos, y concretamente a las experiencias andinas, tales como Ecuador y Bolivia, quienes han incorporado en sus Constituciones el Buen Vivir, situación que está solo en el nivel de propuesta instituida. 
La visión de Tortosa aunque acercándose a un momento de ruptura, cuando plantea las propuestas constitucionales del Buen Vivir, no dan el quiebre definitivo con el concepto de Desarrollo.

La propuesta de Decrecimiento de Serge Latouche, por otro lado significa un quiebre definitivo con el Desarrollo, se contra-pone (ponerse de frente), cuando dice que debemos ir hacia una sociedad del decrecimiento:

“... precisemos en seguida que el decrecimiento no es un concepto, en el sentido tradicional del término, en todo caso, y no se puede hablar exactamente de "teoría del decrecimiento" tal como lo han hecho los economista de las teoría del crecimiento (...) Es un slogan político con implicaciones teóricas (...) que tiene como objetivo romper el lenguaje estereotipado de los adictos al productivismo" (Latouche, Sergio, 2008, p. 16).

Lo que propone en realidad Latouche (2003), es salir del crecimiento por el crecimiento. No como una propuesta teórica alternativa al desarrollo, sino como una nueva lógica de crecimiento. Para demostrar el peso que estamos cargando sobre el planeta y la huella ecológica, Latouche (2003), hace referencia que un ciudadano norteamericano consume un promedio de 8,6 hectáreas, un canadiense 7,2 hectáreas, un europeo medio 4,5. Lo que se necesita es bajar a unas promedio 1,4 hectáreas, considerando que la población se mantenga como hasta el momento. Es decir que siendo conservadores en el sentido que la población no crezca, ya tenemos problemas por el consumo desigual y exagerado por parte de los países centrales.

Siguiendo en la línea del quiebre con el desarrollo encontramos que, más allá de la institucionalización del "Sumakawsay" en las Constituciones, este concepto adquiere sentido siempre que renunciemos a nuestro modo de vida consumista (Latouche 2003). En otras palabras, "vivir de otro modo para vivir mejor" (Latouche, 2003), como diría uno de los teóricos indígenistas:

"El Sumakawsay más precisamente es: el convivir Sagrado y Holístico en la armonía y el equilibrio. Este Kawsay que es la Energía Viva que difumina y reproduce la vida, es el Convivir con el espíritu Total (Gran Espíritu) que se manifiesta materialmente generando la Vida. Es por eso que no existe diferencia entre Vida y Espíritu, entre Vida y Dios, entre Vida y Naturaleza, entre Vida y materia, todas ellas son diferentes palabras para expresar lo mismo pero en diferentes estados o forma (inmanencia) (Oviedo, 2012, p. 220)

Un pensamiento alternativo al desarrollo implica una ruptura con la propuesta, darse la vuelta y marchar contra corriente, pues, como vemos todas las formas de intento por arreglar lo que está mal en el desarrollo terminan alineándose al desarrollo. Es el momento de la práctica, más que lo discursivo, como dice Villasante (2006), los movimientos "alter-mundistas" están en las esperanzas y en las prácticas que surgen desde la base, como una experiencia de vida: 
"Lo que pueda surgir parece más una construcción desde abajo y con pasos demostrados empíricamente, a partir de las experiencias parciales de alternativas (bancos locales, redes de comercialización, formas de auto-gestión operativas, bancos de semillas, ocupaciones de tierras, escuelas de ciudadanía, aplicación de tecnologías blandas, metodologías participativas, etc.), y con el aval de algunos movimientos concretos (por la soberanía alimentaria, "desarrollo del tercer sector", identidades indígenas, etc.)” (Villasante, 2006, p. 75)

Es necesario recuperar el equilibrio entre los seres humanos, la naturaleza y los animales para trazar el camino de una nueva experiencia de vida. Solo con la participación de cada uno de los elementos citados y considerados como sujetos, podremos lograr el equilibrio, con sabiduría (Yachay) y amor (Kuyay/Munay) (Oviedo, 2012). En este proceso la sociedad de crecimiento no es sustentable, pues, acumula infinitamente en una biósfera finita (Latouche, 2003) y de lo que se trata es de pasar de un sistema económico único a una economía de sistema (Naredo, 2009). "En suma, lo que está en juego es; si, para racionalizar la gestión del mundo en que vivimos, el razonamiento económico debe seguir girando en torno al núcleo de los valores mercantiles o si por el contrario debe desplazar su centro de gravedad hacia los condicionantes del universo físico e institucional que lo envuelve" (Naredo, 2009, p. 84). Además de los debates sobre "alternativas al desarrollo", "decrecimiento" o "sumak kawsay", otros movimientos se han puesto a experimentar como se puede lograr un desenvolvimiento de los seres humanos en armonía con la naturaleza. Aquí se puede citar al movimiento "eco-socialista" (o el más local de "comunidades en transición") sobre todo en Europa; y en América Latina la presencia silenciosa por el momento pero profunda en testimonio de los Zapatistas al sur de México en el Estado de Chiapas, que tienen una experiencia en la implementación de los municipios autónomos; o el del Movimiento de Trabajadores sin Tierra (MST) en Brasil con "acampamentos" y "asentamientos" en casi todo este gran país.

\section{PARTICIPACION SOCIAL EN LA PLANIFICACION DEL DESARROLLO}

La Planificación Participativa es la aplicación de los procedimientos y metodologías de la planificación -como proceso de varias dimensiones y de toma de decisiones para racionalizar la asignación de recursos-, al contexto local, con una amplia participación y apropiación social.

La Planificación participativa se constituye en el instrumento metodológico y operativo que permite la articulación entre el Estado representado por el gobierno local y la sociedad civil, en un proceso de sustentabilidad. De forma sistemática desarrolla actividades para la constante identificación de problemas, demandas, potencialidades y limitaciones, análisis de alternativas, adopción de estrategias, formulación de programas, proyectos y presupuestos, para la posterior ejecución, evaluación de resultados y ajuste permanente de sus acciones. 
Este proceso considera el CAMBIO DE EPOCA, y desde esta hipótesis entenderá las nuevas formas como la gente vive las relaciones de la cultura, la experiencia humana, el poder, los modos de producción, etc. En el concepto de Cambio de Época, existe una brecha generacional bastante importante a considerar para una Planificación. "Una época histórica cambia cuando de manera simultánea se transforma: (I) las relaciones de producción, (II) las relaciones de poder; (III) las formas como las personas viven la experiencia humana; y (IV) la cultura". (Castells, 1998)

\subsection{ESTRATEGIAS PARA IMPULSAR LA PLANIFICACION}

\section{COMUNICACIÓN}

Un elemento fundamental de este proceso será el "Dialogo de Saberes" o "Ecología de saberes" (B. S. Santos), o "Socio-praxis" (T.R. Villasante). No existe conocimiento científico sin el conocimiento de quienes construyen diariamente la ciencia, y también los saberes populares.

El proceso de ENCUENTRO DE SABERES, mediatizado por la comunicación como un instrumento que logra establecer consensos para alinear los intereses comunes y respetar los disensos como aquellas opiniones, formas de concepción de la realidad propias que son parte constitutiva de las identidades.

Esta estrategia permite, por ejemplo, un posicionamiento del Plan de Desarrollo y Ordenamiento Territorial, así como un proceso de legitimación de lo que se construye.

Esta estrategia se enfoca en los medios masivos de comunicación (hablados, escritos y audiovisuales) y actividades grupales, que permiten transmitir a la globalidad de la población, los objetivos, procedimientos y resultados que deben instaurarse para motivar la plena identificación con el Plan de Desarrollo y Ordenamiento Territorial.

\section{PARTICIPACION}

Busca articular y efectivizar la relación Sociedad Civil - Estado, para ir logrando una verdadera democratización y construcción de la sustentabilidad entre Gobiernos Locales, Comunidades y Actores Sociales. 
La aplicación de la Participación propone contribuir a:

- Una retroalimentación permanente entre Gobiernos Locales y las Comunidades, en torno a las políticas y recursos públicos.

- Efectivizar la participación y la autogestión social sobre el destino, manejo y uso de los recursos públicos y la toma de decisiones colectivas.

- Establecer un mecanismo integral para encarar la sustentabilidad, basada en instrumentos de gestión y concertación.

- Involucrar y corresponsabilizar a la sociedad civil en el diseño y construcción de su desarrollo.

- Consolidar una nueva forma de concebir la planificación, con la participación activa y toma de decisión desde los actores locales.

\section{FORMACION}

El proceso de Planificación Participativa debe ser entendido en el marco de la descentralización, pues es urgente que los gobiernos locales autónomos desarrollen sus capacidades, habilidades y actitudes, con la finalidad de atender a su población más cercana.

Construir los gobiernos de cercanía y acercar al Estado hacia los gobiernos locales, para servir de mejor manera a hombres y mujeres es un reto de la Planificación del Desarrollo y del Ordenamiento Territorial.

Desde los gobiernos Locales se ha visto la necesidad de algunos temas de formación con la finalidad de desarrollar una cultura de los derechos (Memoria de talleres del Municipio de Cuenca, 2010). Estos temas son los siguientes:

1. Liderazgo 
2. Gobernabilidad y Participación Ciudadana

3. Gerencia y Administración Pública

4. Manejo de herramientas de Planificación y Gestión

5. Planificación Territorial

6. Desarrollo económico territorial

7. Género, interculturalidad y desarrollo local

\subsection{PARTICIPACION SOCIAL EN LA CONSTITUCIÓN DEL BUEN VIVIR.}

En el año 2008, se elaboró la Nueva Constitución Ecuatoriana con una amplia participación de los sectores sociales, la misma que sería el marco para una posible transformación social.

La Constitución establece en el Titulo IV, Sección Tercera, referente a la Participación y Organización del Poder, Art.100:

"En todos los niveles de Gobiernos se conformarán instancias de participación integradas por autoridades electas, representantes del régimen dependiente y representantes de la sociedad del ámbito territorial de cada nivel del gobierno, que funcionará regida por principios democráticos. La participación en estas instancias se ejerce para:

1. Elaborar planes y políticas nacionales, locales y sectoriales entre los gobiernos y la ciudadanía.

2. Mejorar la calidad de inversión pública y definir agendas de desarrollo.

3. Elaborar presupuestos participativos de los gobiernos

4. Fortalecer la democracia con mecanismos permanentes de transparencia, rendición de cuentas y control social.

5. Promover la formación ciudadana e impulsar procesos de comunicación..." (Constitución Ecuatoriana, 2008)

La Constitución establece en el Título V; Capítulo Primero, referente a la Organización Territorial del Estado en el Art. 241- "la planificación garantizará el ordenamiento territorial y será obligatoria en todos los gobiernos autónomos descentralizados" (Constitución Ecuatoriana 2008).

La Constitución en el Capítulo IV del Régimen de Competencias, en el Artículos 262, 263, 264, 266 y 267 establece la competencia obligatoria de los Gobierno Autónomos Descentralizados, referente a la planificación dice que:

"Los gobiernos parroquiales rurales ejercerán las siguientes competencias exclusivas, sin perjuicio de las adicionales que determine la ley:

1. Planificar el desarrollo de actividades productivas comunitarias, la preservación de la biodiversidad y la protección del ambiente. 
2. Planificar, construir y mantener la infraestructura física, los equipamientos y los espacios públicos de la parroquia, contenidos en los planes de desarrollo e incluidos en los presupuestos participativos anuales.

3. Planificar y mantener, en coordinación con los gobiernos provinciales, la vialidad parroquial rural.

4. Incentivar el desarrollo de actividades productivas comunitarias, la preservación de la biodiversidad y la protección del ambiente

5. Gestionar, coordinar y administrar los servicios públicos que le sean delegados o descentralizados por otros niveles de gobierno.

6. Promover la organización de los ciudadanos de las comunas, recintos y demás asentamientos rurales, con el carácter de organizaciones territoriales de base.

7. Gestionar la cooperación internacional para el cumplimiento de sus competencias". (Constitución Ecuatoriana 2008)

La participación Social y el Buen Vivir, implican una ruptura con los esquemas clásicos de la planificación y de las concepciones del desarrollo, bajo los siguientes supuestos:

1) Por la preferencia del enfoque planificado frente a la evolución espontánea, regida por las leyes del mercado y el juego de los grupos de interés del sistema territorial. En este nuevo marco globalizador es necesario compensar la lógica de la mano invisible del mercado -lógica eminentemente mercantilista y de consumo- con una dúctil manera de vivir la cultura patrimonial en las comunidades rurales.

2) Necesidad de superar la parcialidad y reduccionismo que comporta la planificación sectorial, ya que el desarrollo se plasma en un sistema territorial, que, de acuerdo con la teoría de sistemas, no puede ser entendido ni planificado si no es como un todo. En este sentido, lo que se desarrolla es un territorio en toda su complejidad, en el que la población dispone de una satisfactoria calidad de vida.

3) La problemática rural, como efecto de procesos de constante urbanización y nuevas formas de ruralidad, está alcanzando dimensiones tales que su resolución, desde una única perspectiva, es insuficiente.

4) La globalización de la sociedad actual -con sus procesos de integración regional, procesos acelerados de urbanización, falta de respuestas urgentes a los impactos de las Nueva Tecnologías de Comunicación, introducen notables cambios en las perspectivas de los territorios rurales. Así mismo, surgen nuevas oportunidades y sorprendentes amenazas.

5) El Plan de Desarrollo y Ordenamiento Territorial realizado participativamente es un instrumento de planificación que permite compatibilizar los objetivos de 
desarrollo económico y social con los objetivos de conservación y manejo de los recursos naturales.

La Nueva Constitución de la República del Ecuador, es un Marco Jurídico que abre la posibilidad de iniciar una verdadera Participación Social en la construcción de una sociedad del Buen Vivir, como un paradigma necesario en esta Nueva Época.

\section{BIBLIOGRAFIA}

ASAMBLEA CONSTITUYENTE. 2008Constitución 2008 Dejemos el pasado atrás. Quito - Ecuador.

COMISION MUNDIAL DEL MEDIO AMBIENTE Y DESARROLLO, C. (. (1987). Nuestro Futuro Común. Madrid: Alianza.

Constitución 2008. Publicación Oficial de la Asamblea Constituyente

CORPORACION DE ESTUDIOS Y PUBLICACIONES. 2011. Código Orgánico de Organización Territorial, Autonomía y Descentralización. Quito - Ecuador,

GÓMEZ OREA, Domingo. 2009. MARCO CONCEPTUAL. "Formación en Ordenamiento Territorial. Documento SENPLADES. Quito - Ecuador.

Escobar, A. (2007) La Invención del Tercer Mundo Construcción y deconstrucción del desarrollo. Venezuela. Edición Fundación Editorial el perro y la rana.

Jiménez, L. M. (1997). Desarrollo Sostenible y Economía Ecológica. España. EDITORIAL SINTESIS, S.A.

Latouche, S. (2008). La apuesta por el decrecimiento:¿ cómo salir del imaginario dominante? (Vol. 273). Icaria Editorial. Recuperado de: http://scholar.google.com.ec

Latouche, S. (2003). Por una sociedad en decrecimiento. Le Monde diplomatique. Edición española, (97). Recuperado de: http://scholar.google.com.ec

MAX-NEEF, M. DESARROLLO A ESCALA HUMANA. (1994). Montevideo, Uruguay. Editorial Nordan - Comunidad.

Max Neff, M. (1993). DESARROLLO A ESCALA HUMANA. Barcelona: Icaria Editorial S.A

Naredo, J.M. (2009). LUCES EN EL LABERINTO AUTOBIOGRAFIA INTELECTUAL Y ALTERNATIVAS A LA CRISIS. Madrid. LOS LIBROS DE LA CATARATA. 
Oviedo, A.M. (2012). QUE ES EL SUMAKAUSAY VITALISMO ANDINO: COSMOCIMIENTO DE LA VIDA. La Paz - Bolivia. SUMAK Editores.

R. Villasante, T. (2006). DESBORDES CREATIVOS. ESTILOS Y ESTRATEGIAS PARA LA TRANSFORMACION SOCIAL. Madrid - España. Los Libros de la Catarata.

Tortosa, J.M. (2011). MAL DESARROLLO Y MAL VIVIR. Quito - Ecuador. Ediciones Abya - Yala.

Tortosa, J.M. (2012). Desigualdad, Conflicto, Violencia. Cuenca. PYDLOS EdicionesUniversidad de Cuenca.

Urteaga Olano, E. (2008). El debate internacional sobre el desarrollo sostenible. Revistas -investigaciones Geográficas No. 46. Recuperado en: http://rua.ua.es/dspace/bitstream/10045/14610/1/IG_46_07.pdf

Sen, A. (2012). DESARROLLO Y LIBERTAD. Colombia. Editorial Planeta Colombiana S.A.

Sen, A. (1997). Desarrollo y Libertad. Bogota: Planeta Colombiana S.A 